\title{
ETAPAS INICIAIS DO PROJETO DE UM CARRINHO PARA BEBÊ
}

\author{
Andressa Schneider Alves \\ Universidade Federal do Rio Grande do Sul \\ andressa.alves@ifsc.edu.br \\ Bruna Lummertz \\ Universidade Federal do Rio Grande do Sul \\ Brunalummertz28@gmail.com \\ Carina Carlan da Costa \\ Universidade Federal do Rio Grande do Sul \\ carinapcarlan@gmail.com \\ José Luís Farinatti Aymone \\ Universidade Federal do Rio Grande do Sul \\ aymone@ufrgs.br \\ Régio Pierre da Silva \\ Universidade Federal do Rio Grande do Sul \\ régio@ufrgs.br \\ Tânia Luisa Koltermann da Silva \\ Universidade Federal do Rio Grande do Sul \\ tania.koltermann@ufrgs.br
}

\begin{abstract}
Resumo: O presente artigo tem como objetivo apresentar as etapas de planejamento de produto e projeto conceitual de um carrinho para bebê realizado na disciplina "Processo de Geração e Seleção de Concepções de Projeto" junto ao programa de Pós-Graduação em Design da Universidade Federal do Rio Grande do Sul (UFRGS) em 2013. A metodologia utilizada constitui-se das seguintes etapas: pesquisa bibliográfica, geração de ideias a partir de um jogo que utiliza técnicas criativas, geração e seleção de alternativas. Os resultados alcançados comprovam os benefícios da metodologia empregada e da utilização do jogo na etapa de geração de ideias.
\end{abstract}

Palavras-chave: Processo de Desenvolvimento de Produtos, Técnicas criativas, Design.

Abstract: The present article aims to present the stages of product planning and conceptual design of a baby carriage developed in the course "Generation Process and Conceptions Selection of Design" of the 
Postgraduate Program in Design at the Federal University of Rio Grande do Sul (UFRGS) in 2013. The methodology employed has the following stages: literature review, idea generation from a game that uses creative techniques, alternative generation and alternative selection. The results achieved demonstrate the benefits of the methodology employed and the benefits the game use in the idea generation stage.

Keywords: Product Development Process, Creative techniques, Design.

\section{INTRODUÇÃO}

Diferentemente do homem pré-histórico que criou a pedra lascada e a pedra polida de modo intuitivo, a partir de um determinado período da história, não foi mais possível desenvolver os produtos necessários apenas de modo individualizado e empírico. O design tornou-se necessário e fundamental no momento em que um único artífice deixou de ser responsável por todos os estágios da manufatura. A introdução do design ocorreu junto com a divisão do trabalho. Surgiu assim, a necessidade de um conjunto de instruções para orientar o artesão, o projeto (FORTY, 2007).

A partir da década de 1960 iniciou-se o estudo do processo de desenvolvimento de produtos (PDP) como uma disciplina, de modo mais sistemático. Na década de 1980, o desenvolvimento de produtos industriais foi considerado uma atividade de grande importância, e os métodos e as ferramentas desenvolvidas foram resultados de pesquisas na área. Como consequência, atualmente, existem diversas metodologias para o processo de desenvolvimento de produtos, como as de Baxter (2000), Munari (1998), Bonsiepe, Kellner e Poessnecker (1984) e Back et al. (2008).

Pela quantidade de metodologias e técnicas criativas, poderia se supor, que houvesse também um número elevado de materiais bibliográficos que apresentassem o processo pelo qual uma ideia resultou em um determinado produto. Os produtos aparecem finalizados e informa-se sobre suas diversas qualidades, estéticas, funcionais e simbólicas. Porém, raramente são apresentados os processos pelo qual se desenvolveu aquele produto.

Além da falta de materiais bibliográficos sobre o processo de desenvolvimento de produtos, e apesar do grande desenvolvimento da área do design ao longo dos últimos 300 anos, Cardoso (2012) ressalta que é necessária a revisão imediata do processo de ensino de design. É preciso resgatar e tentar diminuir o distanciamento e a separação dos métodos de ensino com a realidade do meio profissional, do mercado de trabalho e das indústrias.

Schön (2000) também questiona o sistema de ensino da educação profissional e se o conhecimento profissional ensinado nas escolas prepara os estudantes para as demandas reais da prática. O que Cardoso (2012) pretende definir pela palavra separação, Schön (2000) define pelo termo "talento artístico". Segundo o autor, o "talento artístico" é a competência que os profissionais mais destacados no meio profissional demonstram em situações da prática permeada de incertezas, singularidades e conflitos de valores, que não são resolvidos pela racionalidade técnica empregada no ensino profissional atual. O trabalho de Schön (2000) é fundamentado nos estudos de Dewey (1974) sobre a aprendizagem através do fazer. 
Dessa forma, o presente artigo pretende contribuir com as lacunas existentes. Apresentam-se as etapas iniciais do processo de desenvolvimento de produto (PDP) que compreendem as fases de geração de ideias, geração e seleção de alternativas. Essas fases foram desenvolvidas através de uma forma diferente de ensino, a aprendizagem através do fazer. As próximas seções deste artigo descrevem as etapas de planejamento de produto e projeto conceitual, desenvolvidas para um produto específico, em sala de aula, pelos autores deste trabalho, no Programa de PósGraduação em Design da Universidade Federal do Rio Grande do Sul (UFRGS).

\section{PROJETO CARRINHO PARA BEBÊ}

O processo de desenvolvimento de produtos é composto pelas fases de planejamento (planejamento do projeto), elaboração do projeto do produto (projeto informacional, projeto conceitual, projeto preliminar e projeto detalhado) e implementação do lote inicial (preparação da produção, lançamento e validação) (BACK et al., 2008).

Para apoiar as etapas de planejamento do projeto, projeto informacional e do projeto conceitual existem inúmeras técnicas criativas, como, brainstorming, MESCRAI, analogias, método sinético, listagem de atributos, análise morfológica, mapa mental e método Delphi. Essas técnicas auxiliam o processo criativo e a coleta e classificação de ideias existentes. Muitas dessas técnicas podem ser empregadas em outras fases do desenvolvimento de produtos, já que o processo criativo não está limitado a uma única etapa (BACK et al., 2008).

Kowaltowski et al. (2011) aborda o processo de projeto e apresenta 261 métodos e técnicas de apoio à criação. Pela diversidade de técnicas criativas existentes, Baxter (2000) sugere que o ideal é que o designer saiba empregar com eficiência todas as técnicas, conhecendo os benefícios e desvantagens de cada uma. Dessa forma, a escolha deve ser de acordo com a técnica mais adequada para cada problema.

Com o propósito de desenvolver um produto criativo, trabalhar conceitos teóricos e aplicar técnicas criativas nas etapas iniciais do processo de desenvolvimento de produtos, desenvolveram-se as etapas de geração de ideias, geração de alternativas e seleção de alternativas para um projeto. O objetivo do projeto foi desenvolver um meio de transporte para crianças na faixa etária de um ano, para ser utilizado por pais ou parentes e percorrer um trajeto curto, como o da casa até a escola.

O desenvolvimento de um meio de transporte para bebês e crianças não é um projeto simples. A reportagem Teste de fogo: conheça prós e contras de seis modelos de carrinhos, de Marina (2013), do jornal Folha de São Paulo, apresenta um teste realizado com 6 modelos de carrinhos para bebês. Os produtos foram sujeitos à subida de ladeiras, ruas de paralelepípedo e calçadas esburacadas. Todos os produtos obtiveram pontos positivos e negativos. Nenhum carrinho foi considerado totalmente satisfatório, o que evidencia a dificuldade em se desenvolver um produto que consiga atender todas as necessidades. Para o desenvolvimento do produto, também é preciso satisfazer os requisitos definidos nas normas NBR 14389 e NBR 14440, que têm como principal objetivo a prevenção de acidentes com crianças e bebês (INMETRO, 2012).

Para os desafios de design de produtos da atualidade, Cardoso (2012) defende que não existem receitas formais para a resolução dos problemas. Não existem cores pré-definidas, materiais indispensáveis, proporções, ou frases como "Menos é mais" 
de Mies Van der Rohe ou "A forma segue a função" de Louis Sullivan, que solucionarão os enormes desafios do mundo complexo atual (CARDOSO, 2012).

\subsection{Geração de ideias}

A etapa de geração de ideias, para o meio de transporte de crianças, foi realizada através de um jogo, desenvolvido por Cardozo (2012). O jogo tem fases sistemáticas, a cada rodada as ideias são desenhadas e expostas para os outros participantes. Cada grupo explica as ideias e argumenta os pontos positivos. Os outros grupos são responsáveis pela crítica e complementação das ideias. Participaram dessa etapa um grupo de 18 pessoas divididas em 6 trios. Cardoso (2012), quando se refere ao design para um mundo complexo, acredita que as melhores soluções costumam vir do trabalho em equipe e em redes, pois assim se dá o contato com a informação.

O jogo proposto por Cardozo (2012) aplica, de forma subsequente, quatro técnicas criativas: brainstorming, gatilho de ideias, TRIZ e seis chapéus. Cada uma dessas técnicas criativas é aplicada em uma das rodadas do jogo.

Back et al. (2008) classifica o brainstorming como método intuitivo e ressalta que esse tipo de método é benéfico para disparar ideias na etapa de geração inicial de soluções. A técnica gatilho de ideias também pode ser classificada como um método intuitivo. De acordo com Back et al. (2008) é difícil definir os melhores métodos entre todos existentes, já que a execução e os resultados dependem dos participantes da equipe e do tipo de projeto.

O método brainstorming possui algumas vantagens, como a grande aceitação, a possibilidade de ser aplicado em qualquer fase de desenvolvimento do produto e a condição de pensar de modo fora do habitual para propiciar o surgimento de ideias diversas (BACK et al., 2008; BAXTER, 2000).

A técnica de gatilho de ideias tem como princípio trazer um conceito não relacionado com o problema e forçar conexões ou similaridades entre eles (HARRIS, 2002). Harris (2002) ressalta que essa técnica exige um perfil de pessoas com paciência e entusiasmo, já que cria associações estranhas entre conceitos muito diferentes.

Após esses dois métodos intuitivos, foram aplicados no jogo dois métodos sistemáticos: a TRIZ e seis chapéus. Segundo Back et al. (2008) os métodos sistemáticos “(...) seguem uma sequência lógica e sistematizada de atividades que levam a soluções alternativas para um determinado problema". A teoria de solução inventiva de problemas, conhecida por TRIZ, foi desenvolvida através da observação da prática de resolução de problemas descritos nos pedidos de patente. Através dessa observação foram definidos princípios inventivos, porém nem todos os princípios se aplicam a todo tipo de problema (BACK et al., 2008). No jogo, os 40 tipos de princípios aparecem em cartões e são divididos entre os grupos. Cada grupo escolhe três, entre os princípios inventivos que recebe. Os princípios inventivos escolhidos foram: aninhamento, inversão e segmentação. A partir do detalhamento e exemplificação de cada um dos princípios inventivos, desenvolveu-se uma ideia de produto para cada princípio.

A próxima técnica empregada foi o método dos seis chapéus, porém dos seis é utilizado apenas um chapéu, o preto. O chapéu preto representa a lógica negativa e é indicado para identificar barreiras. Nessa técnica, nenhum chapéu é mais importante do que o outro (PLENTZ, 2011). Assim, a utilização de apenas uma parte da técnica não pareceu adequada para o jogo. 
Durante o jogo buscou-se um olhar desprendido do objeto, conforme defende Cardoso (2012), para que não seja condicionado às premissas, assim podendo gerar novas ideias. Depois de quatro rodadas e da utilização das técnicas criativas descritas anteriormente, gerou-se 15 ideias no grupo azul composto por três pessoas - autores deste artigo. Os outros grupos também geraram um número semelhante de ideias. Para a etapa final do jogo definem-se duas ideias e defendem-se os aspectos positivos da ideia perante o grupo e buscam-se formas de melhorar os pontos negativos identificados pelos outros participantes. Após a defesa, cada grupo elegeu a melhor ideia.

A Figura 1 apresenta a ideia gerada pelo grupo azul no final do jogo. A ideia consiste em um carrinho para bebê com forma esférica, capota reclinável, com puxador para transporte retrátil e com compartimento interno para guardar objetos e brinquedos.

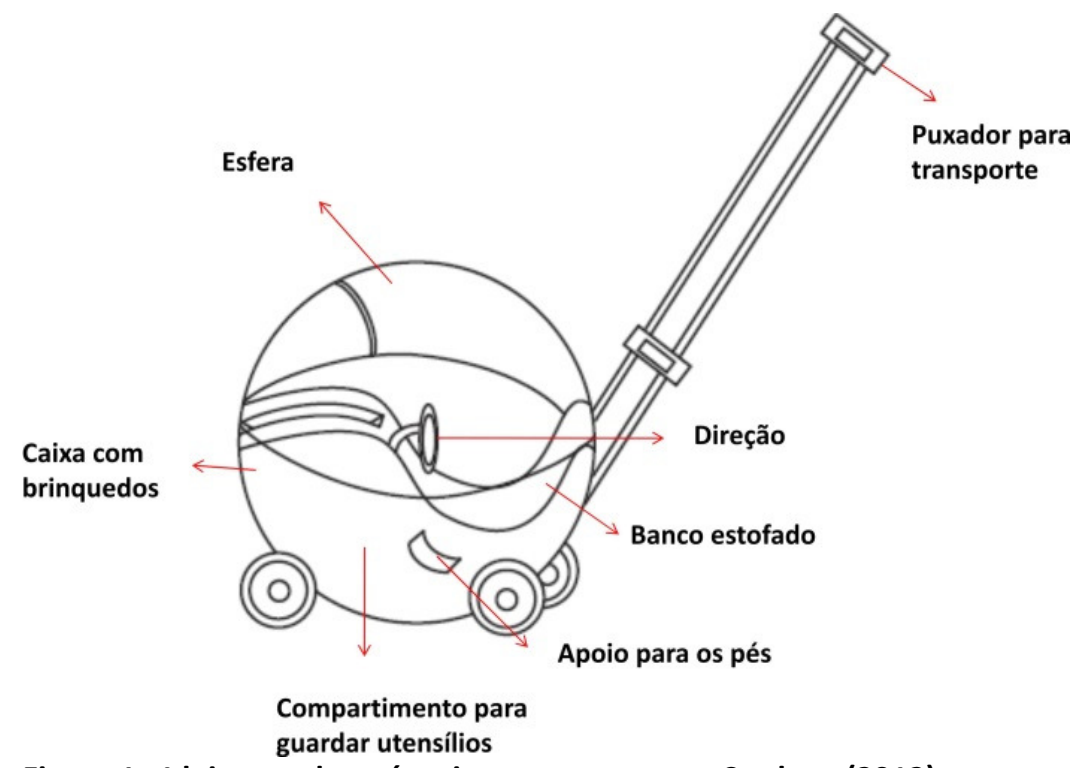

Figura 1 - Ideia gerada após o jogo proposto por Cardozo (2012)

Fonte: Elaborado pelos autores, com base na pesquisa realizada

\subsection{Geração de alternativas}

A etapa de geração de alternativas iniciou com a construção da estrutura de funções. A partir da função global do problema: transportar bebê na faixa etária de 1 ano de idade, foi realizado o desdobramento em subfunções de níveis menores de complexidade. A Figura 2 apresenta o fluxo de funções para o problema do carrinho de bebê.

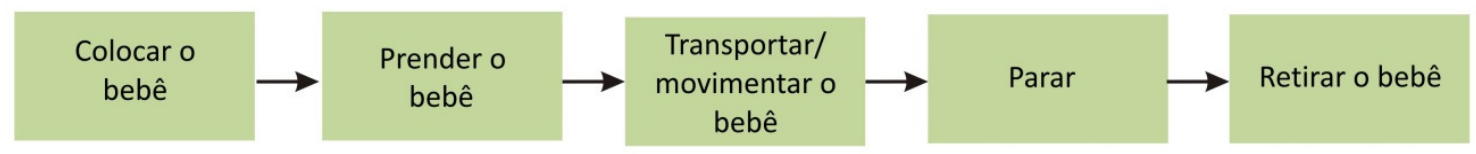

Figura 2 - Fluxo de funções

Fonte: Elaborado pelos autores, com base na pesquisa realizada

O fluxo de funções do problema auxiliou na definição das variáveis relacionadas ao problema. Segundo Back et al. (2008), a estrutura de funções compõem uma das etapas mais importantes do projeto conceitual. 0 propósito da estrutura de funções é 
facilitar a descoberta de soluções uma vez que se trabalha com subfunções, um nível de menor complexidade.

Após a definição do fluxo de funções construiu-se a matriz morfológica para problema. Através da matriz morfológica analisaram-se diversas combinações entre os elementos do produto. Segundo Baxter (2000), um fator que beneficia o uso dessa técnica está no estudo sistemático de todas as combinações possíveis e viáveis. 0 autor ainda defende que o uso da técnica evita que se deixe de examinar algumas possibilidades, o que na área do design é vantajoso no desenvolvimento de produtos inéditos. A Figura 3 apresenta a matriz morfológica desenvolvida com as variáveis na coluna da esquerda e os princípios de solução nas outras colunas.

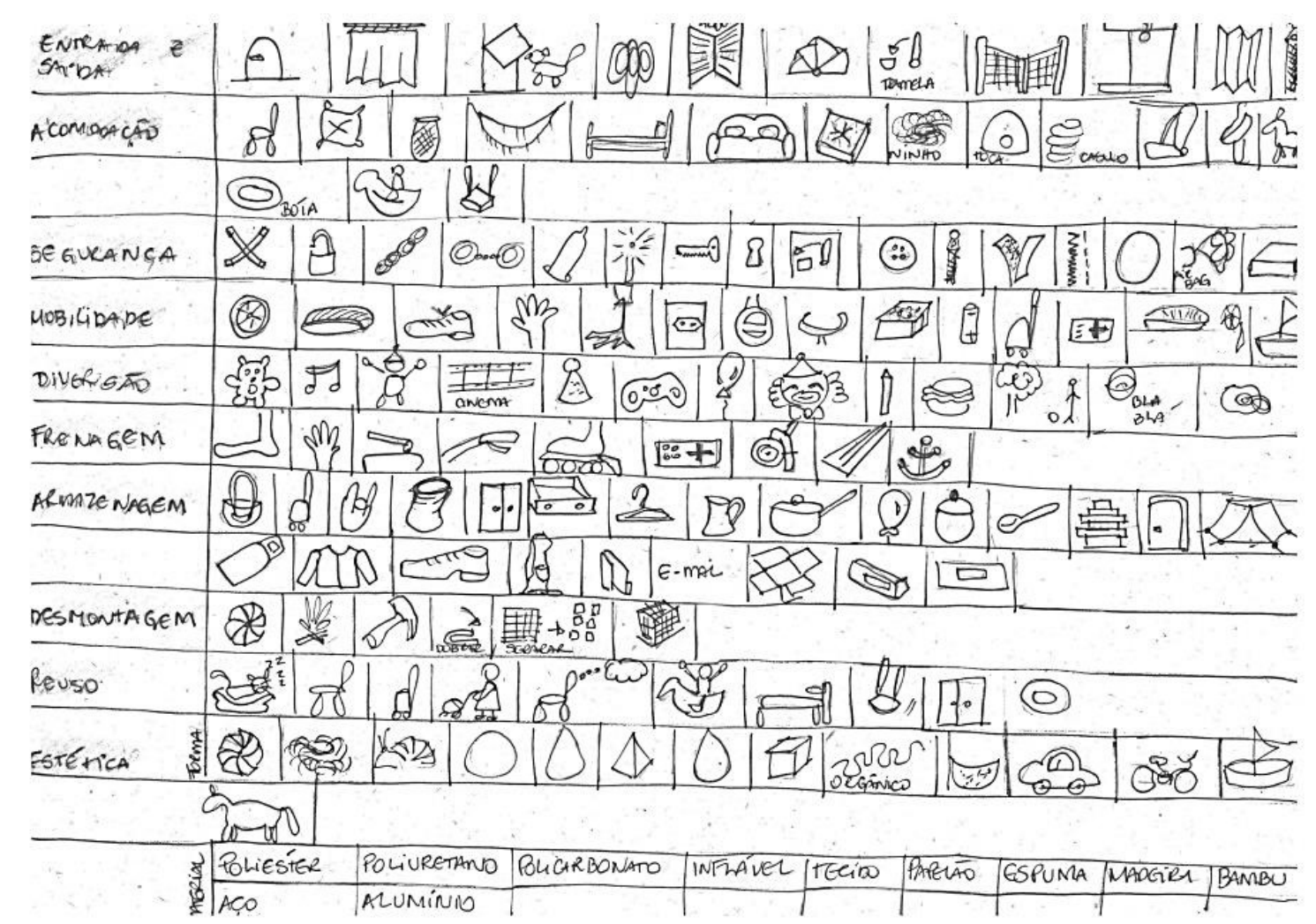

Figura 3 - Matriz morfológica

Fonte: Elaborado pelos autores, com base na pesquisa realizada

Uma das subfunções previstas na matriz morfológica é o reuso, para que depois que o objeto deixe de ser útil para executar a tarefa para o qual foi desenvolvido, possa servir para outro fim. Cardoso (2012) evidencia que estamos em processo de "(...) sermos soterrados pelo lixo que produzimos". O autor define lixo como matéria desprovida de sentido ou propósito. Dessa forma, se o objeto tiver outra possibilidade de utilização após o uso previsto inicialmente, terá o seu ciclo de vida ampliado.

A partir da combinação de diferentes princípios de solução da matriz morfológica foram geradas sete alternativas para o problema proposto. A seguir são apresentadas as alternativas e ao lado uma tabela com os princípios da matriz morfológica utilizados naquela alternativa. 
ALTERNATIVA 1
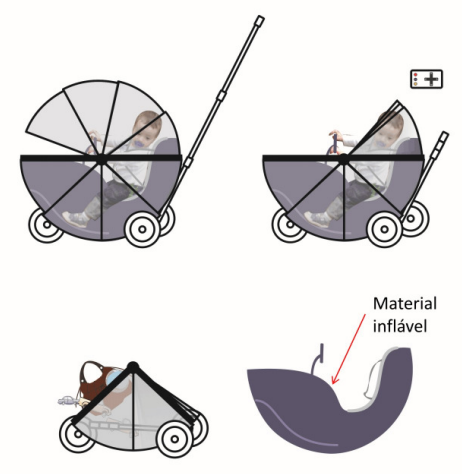

ALTERNATIVA 3

Cápsula

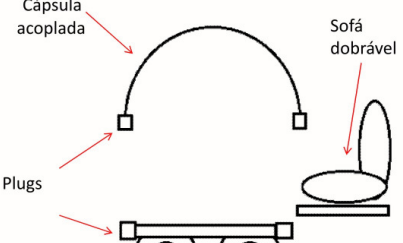

(छ) (®)

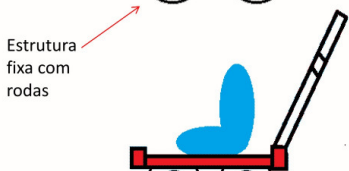

(Q) (®)

ALTERNATIVA 5

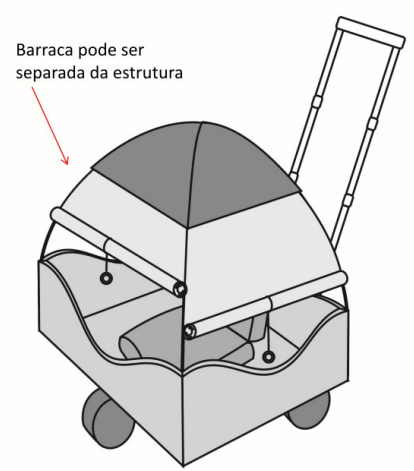

ALTERNATIVA 7

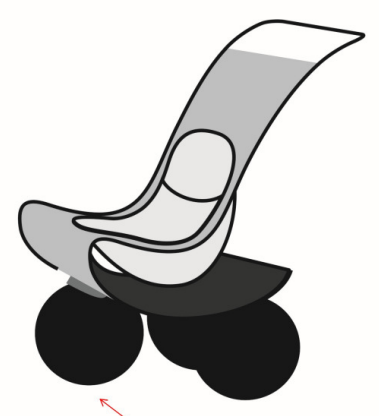

Rodas podem ser retiradas torna-se uma cadeira de

Figura 4 - Geração de alternativas

Fonte: Elaborado pelos autores, com base na pesquisa realizada

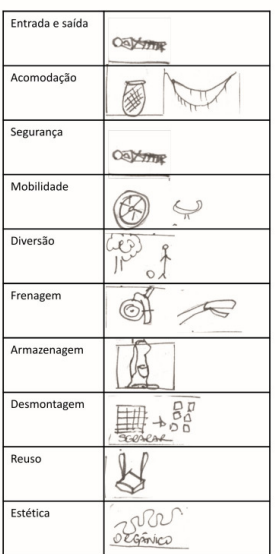

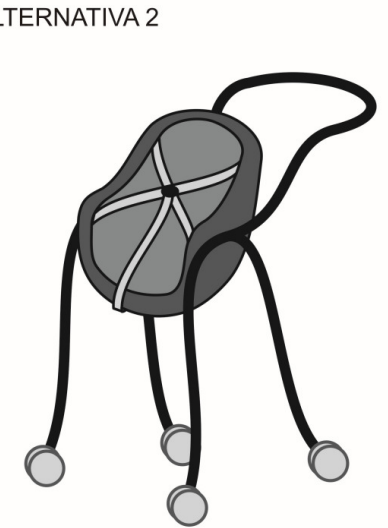
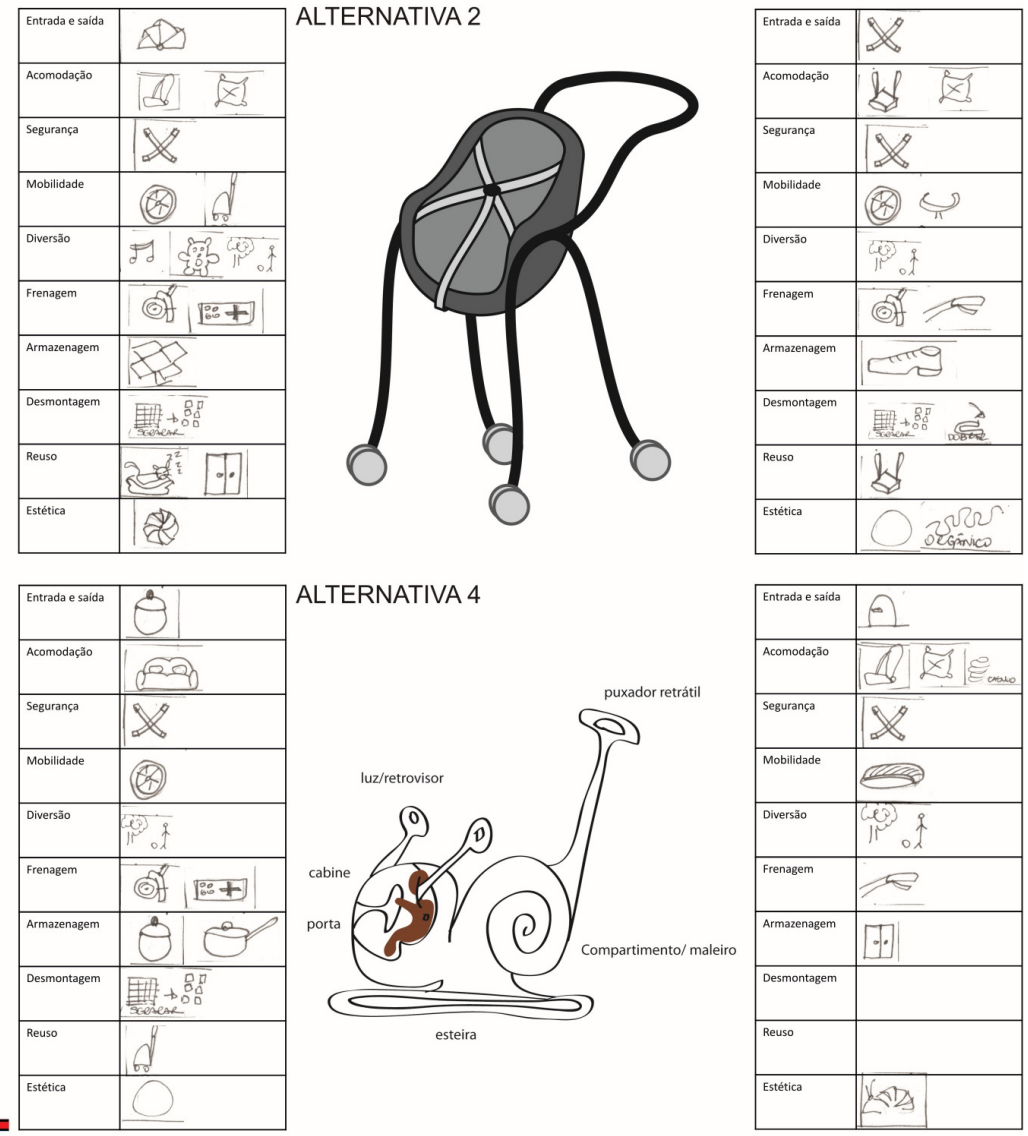

ALTERNATIVA 4

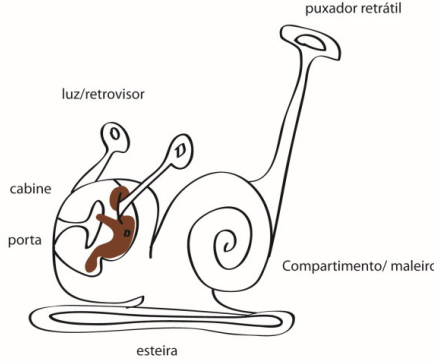

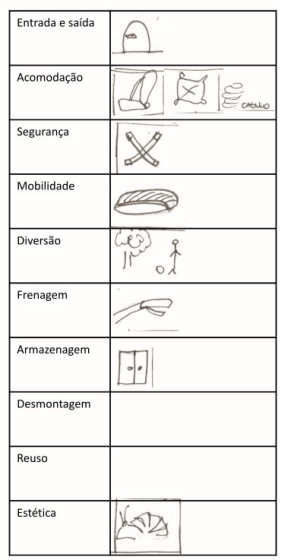

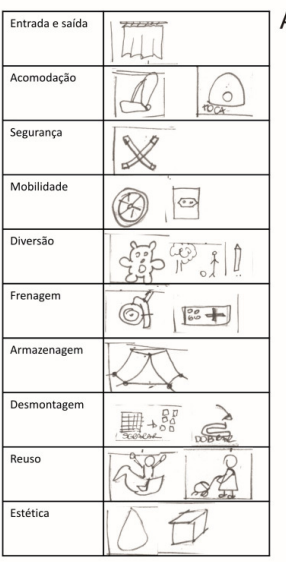

ALTERNATIVA 6

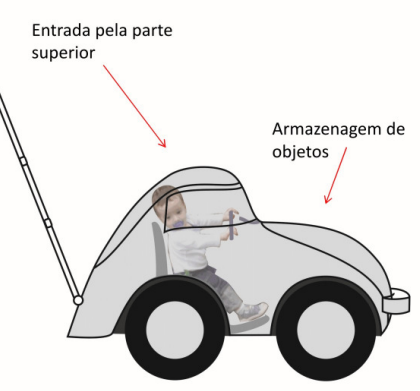

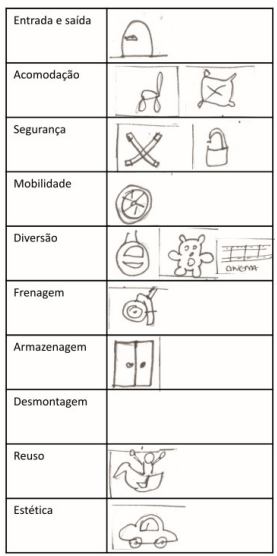




\subsection{Seleção de alternativas}

No projeto de produtos, a etapa de avaliação de uma ideia nem sempre é simples, sobretudo se ela ocorrer antes do desenvolvimento do protótipo. 0 desenvolvimento do protótipo e do projeto conceitual envolvem custo e tempo significativos (BAXTER, 2000).

Para sistematizar o processo de seleção de alternativas geradas na etapa anterior e definir as mais adequadas para o problema proposto, tendo como objetivo evitar a escolha por método empírico, desenvolveu-se uma matriz de Pugh (1991 apud BACK et al., 2008).

O método Pugh é considerado por Back et al. (2008) como simples e de fácil aplicação e permite evidenciar as melhores soluções. A Tabela 1 apresenta a triagem de concepções através do método Pugh. Na primeira coluna estão os critérios generalizados, que foram, neste primeiro momento, considerados com igual importância ou peso. Para construir a matriz, adotou-se como referência um produto concorrente, o carrinho de bebê modelo Trio I-Move da marca Chicco ${ }^{1}$. O produto concorrente está na segunda coluna, denominada de coluna de referência, e para cada critério registrou-se o valor zero (0). Para as outras concepções, cada critério foi comparado com o correspondente da solução de referência e, se considerado melhor, atribuiu-se um sinal positivo (+), caso igual, registrou-se com zero (0) e, caso pior, definiu-se um sinal negativo (-). A valoração das concepções foi efetuada por consenso entre os participantes.

Tabela 1 - Triagem de concepções através do método Pugh

\begin{tabular}{|c|c|c|c|c|c|c|c|c|}
\hline CRITÉRIOS & $\begin{array}{l}\text { Referência } \\
\text { Carrinho } \\
\text { Chicco }\end{array}$ & $\begin{array}{l}\text { Carrinho } \\
\text { tatu bola }\end{array}$ & $\begin{array}{l}\text { Carrinho } \\
\text { com } \\
\text { balanço }\end{array}$ & $\begin{array}{l}\text { Carrinho } \\
\text { com } \\
\text { cápsula }\end{array}$ & $\begin{array}{l}\text { Carrinho } \\
\text { caramujo }\end{array}$ & $\begin{array}{l}\text { Carrinho } \\
\text { barraca }\end{array}$ & $\begin{array}{l}\text { Carrinho } \\
\text { em forma } \\
\text { de carro }\end{array}$ & $\begin{array}{l}\text { Carrinho } \\
\text { balanço } \\
\text { canguru }\end{array}$ \\
\hline Segurança & 0 & + & - & 0 & - & + & 0 & 0 \\
\hline Conforto & 0 & 0 & 0 & 0 & 0 & 0 & 0 & - \\
\hline Facilidade de uso & 0 & + & - & - & - & 0 & - & - \\
\hline $\begin{array}{l}\text { Facilidade de } \\
\text { manutenção }\end{array}$ & 0 & 0 & 0 & 0 & - & 0 & 0 & 0 \\
\hline Boa aparência & 0 & + & 0 & + & + & + & + & + \\
\hline Viabilidade técnica & 0 & 0 & 0 & 0 & 0 & + & 0 & 0 \\
\hline Baixo custo & 0 & 0 & + & + & 0 & + & + & + \\
\hline Sustentável & 0 & + & + & + & + & + & 0 & + \\
\hline Soma de (+) & $0(+)$ & $4(+)$ & $2(+)$ & $3(+)$ & $2(+)$ & $5(+)$ & $2(+)$ & $3(+)$ \\
\hline Soma de (-) & $0(-)$ & $0(-)$ & $2(-)$ & $1(-)$ & $3(-)$ & $0(-)$ & $1(-)$ & $2(-)$ \\
\hline Soma de (0) & $8(0)$ & $4(0)$ & $4(0)$ & $4(0)$ & $3(0)$ & $3(0)$ & $5(0)$ & $3(0)$ \\
\hline Resultado final (+) + (-) & $0(+)$ & $4(+)$ & $0(+)$ & $2(+)$ & $1(-)$ & $5(+)$ & $1(+)$ & $1(+)$ \\
\hline
\end{tabular}

Fonte: Elaborado pelos autores, com base na pesquisa realizada

Depois de avaliados todos os critérios e preenchida toda a matriz, foram somados os conceitos atribuídos para cada concepção. Através dos dados obtidos pode-se verificar as melhores soluções e as não satisfatórias. As concepções carrinho

\footnotetext{
${ }^{1}$ Disponível em: <http://www.chicco.com.br/ProdottiChicco/SchedaProdotto/tabid/978/art/06079 195950000/Default.aspx>. Acesso em 01 jul. 2013.
} 
tatu bola, carrinho com cápsula, carrinho barraca, carrinho em forma de carro e carrinho balanço canguru foram destacadas para estudos mais aprofundados na segunda fase do processo de seleção.

Após a construção da matriz de Pugh, é recomendado por Back et al. (2008) que as alternativas viáveis sejam investigadas com o objetivo de examinar as possibilidades de gerar melhores soluções a partir da combinação de duas opções ou melhorar alguma concepção.

É recomendado que, a partir do resultado da matriz de Pugh e após a revisão dos projetos conceituais, sejam desenvolvidos os protótipos para as soluções satisfatórias. Após essa etapa, passa-se para a determinação dos pesos dos critérios (BACK et al., 2008).

Os critérios são estabelecidos com referência nas necessidades dos usuários e nas especificações de projeto. Normalmente, os critérios não possuem o mesmo grau de importância, não sendo possível assim determinar o mesmo peso para todos (BACK et al., 2008).

Para a avaliação dos pesos construiu-se uma matriz de avaliação por comparação aos pares (Tab. 2). Na matriz, os critérios de seleção foram dispostos nas linhas e nas colunas. Os valores atribuídos foram 0; 0,5 e 1. Comparou-se cada critério com os outros e definiu-se qual o mais importante. O valor 1 foi atribuído ao mais importante e o valor 0 ao outro. Quando os dois critérios foram considerados tendo o mesmo grau de importância, atribuiu-se o valor de 0,5 para cada um.

Tabela 2 - Matriz de avaliação dos pesos por comparação aos pares

\begin{tabular}{|c|c|c|c|c|c|c|c|c|c|c|c|}
\hline & & \multicolumn{8}{|c|}{ Critérios } & \multirow[b]{2}{*}{$\begin{array}{l}\text { Soma da } \\
\text { linha }\end{array}$} & \multirow[b]{2}{*}{ Pesos } \\
\hline & & 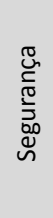 & 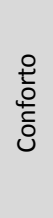 & 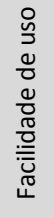 & 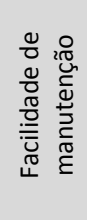 & 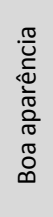 & 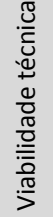 & \begin{tabular}{l}
0 \\
\multirow{n}{n}{} \\
0 \\
0 \\
0 \\
$\frac{x}{\pi}$ \\
$\infty$
\end{tabular} & 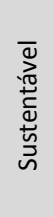 & & \\
\hline \multirow{8}{*}{ 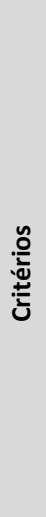 } & Segurança & --- & 1 & 1 & 1 & 1 & 0,5 & 1 & 1 & 6,5 & 0,232 \\
\hline & Conforto & 0 & --- & 0,5 & 1 & 1 & 0 & 0,5 & 0,5 & 3,5 & 0,125 \\
\hline & $\begin{array}{l}\text { Facilidade de } \\
\text { uso }\end{array}$ & 0 & 0,5 & --- & 1 & 1 & 0 & 0,5 & 0,5 & 3,5 & 0,125 \\
\hline & $\begin{array}{l}\text { Facilidade de } \\
\text { manutenção }\end{array}$ & 0 & 0 & 0 & --- & 0,5 & 0 & 0,5 & 0,5 & 1,5 & 0,053 \\
\hline & Boa aparência & 0 & 0 & 0 & 0,5 & --- & 0 & 0,5 & 0,5 & 1,5 & 0,053 \\
\hline & $\begin{array}{l}\text { Viabilidade } \\
\text { técnica }\end{array}$ & 0,5 & 1 & 1 & 1 & 1 & --- & 1 & 1 & 6,5 & 0,232 \\
\hline & Baixo custo & 0 & 0,5 & 0,5 & 0,5 & 0,5 & 0 & --- & 0,5 & 2,5 & 0,089 \\
\hline & Sustentável & 0 & 0,5 & 0,5 & 0,5 & 0,5 & 0 & 0,5 & --- & 2,5 & 0,089 \\
\hline
\end{tabular}

Fonte: Elaborado pelos autores, com base na pesquisa realizada

Após a definição dos valores para cada critério, somaram-se os valores de cada linha, o resultado dessa soma é denominado de peso absoluto. Para obter os pesos relativos, valores da última coluna, dividiu-se o peso absoluto de cada linha pela soma total de todos os pesos absolutos. 
Outra etapa necessária para o processo de seleção das alternativas é a valoração dos critérios. Optou-se por utilizar uma escala de 1 a 5 para avaliação dos critérios, conforme mostra o Quadro 1.

Quadro 1 - Valoração dos critérios

\begin{tabular}{|c|c|}
\hline Valoração qualitativa dos critérios & Valoração numérica dos critérios \\
\hline Satisfatório & 1 \\
\hline Regular & 2 \\
\hline Bom & 3 \\
\hline Muito bom & 4 \\
\hline Excelente & 5 \\
\hline
\end{tabular}

Fonte: Adaptado de Back et al. (2008)

Terminada a valoração e a definição dos pesos de importância para os critérios, a etapa seguinte é o cálculo do valor da função utilidade das concepções. 0 recomendado, como citado anteriormente, é que nesta etapa o projeto conceitual já tenha sido revisto e os protótipos desenvolvidos para as melhores soluções. Para fazer uma simulação da segunda fase do processo de seleção, foram utilizadas as três melhores concepções apresentadas na Tabela 1. Essas concepções foram usadas para montar a Tabela 3, de determinação dos valores da função utilidade das concepções do produto.

Na primeira coluna da Tabela 3 foram registrados os critérios de seleção específicos, e na segunda coluna os pesos dos critérios. Nas outras colunas, para cada concepção foi atribuído uma valoração para cada critério e multiplicado pelo peso relativo daquele critério.

Tabela 3 - Determinação dos valores da função utilidade das concepções do produto

\begin{tabular}{|c|c|c|c|c|c|c|c|c|c|c|}
\hline \multirow{3}{*}{$\begin{array}{l}\text { Critérios de } \\
\text { seleção }\end{array}$} & \multirow{3}{*}{$\begin{array}{l}\text { Pesos dos } \\
\text { critérios (w) }\end{array}$} & \multicolumn{9}{|c|}{ Concepções geradas } \\
\hline & & \multicolumn{3}{|c|}{ Carrinho Tatu bola } & \multicolumn{3}{|c|}{ Carrinho com cápsula } & \multicolumn{3}{|c|}{ Carrinho barraca } \\
\hline & & A & w & $A * w$ & A & w & $A * w$ & A & w & $A^{*} w$ \\
\hline Segurança & 0,232 & 4 & 0,232 & 0,928 & 3 & 0,232 & 0,696 & 3 & 0,232 & 0,696 \\
\hline Conforto & 0,125 & 4 & 0,125 & 0,5 & 3 & 0,125 & 0,375 & 4 & 0,125 & 0,5 \\
\hline Facilidade de uso & 0,125 & 4 & 0,125 & 0,5 & 2 & 0,125 & 0,25 & 3 & 0,125 & 0,375 \\
\hline $\begin{array}{l}\text { Facilidade de } \\
\text { manutenção }\end{array}$ & 0,053 & 5 & 0,053 & 0,265 & 4 & 0,053 & 0,212 & 4 & 0,053 & 0,212 \\
\hline Boa aparência & 0,053 & 5 & 0,053 & 0,265 & 4 & 0,053 & 0,212 & 4 & 0,053 & 0,212 \\
\hline $\begin{array}{l}\text { Viabilidade } \\
\text { técnica }\end{array}$ & 0,232 & 4 & 0,232 & 0,928 & 5 & 0,232 & 1,16 & 5 & 0,232 & 1,16 \\
\hline Baixo custo & 0,089 & 3 & 0,089 & 0,267 & 3 & 0,089 & 0,267 & 3 & 0,089 & 0,267 \\
\hline Sustentável & 0,089 & 4 & 0,089 & 0,267 & 4 & 0,089 & 0,356 & 4 & 0,089 & 0,356 \\
\hline \multicolumn{2}{|c|}{ Valor da função utilidade } & \multicolumn{3}{|c|}{3,92} & \multicolumn{3}{|c|}{3,528} & \multicolumn{3}{|c|}{3,778} \\
\hline \multicolumn{2}{|c|}{ Ordenação das concepções } & \multicolumn{3}{|c|}{ 1a Posição } & \multicolumn{3}{|c|}{3 a Posição } & \multicolumn{3}{|c|}{ 2a Posição } \\
\hline
\end{tabular}

Fonte: Elaborado pelos autores, com base na pesquisa realizada

Na penúltima linha da Tabela 3 são apresentadas as somas dos resultados obtidos em todos os critérios para cada uma das concepções. Com os valores obtidos é possível definir uma classificação.

É importante considerar que a concepção que obteve a melhor pontuação não deve ser vista como solução definitiva. É recomendada uma análise e validação desses resultados, uma vez que as informações sobre as concepções ainda são muito subjetivas nesta fase. 


\section{CONSIDERAÇÕES FINAIS}

O crescente aumento do número de cursos de graduação e pós-graduação em design no Brasil permite inferir a necessidade de profissionais capacitados para exercer funções de projeto e criatividade, em diversos setores da indústria. A criatividade é uma das mais importantes diferenciações no trabalho de designers, através dela consegue-se buscar novas soluções, materiais, formatos ou apenas novas utilizações para aquilo que já é conhecido. Atualmente, o modelo de desenvolvimento de novos produtos busca novos suportes técnicos e criativos como estratégia de inovação e de diferenciação.

Ocorre que muitos designers pretendem obter resultados criativos a partir de ideias já concebidas, o que resulta apenas em melhorias ou redesign de produtos. Também é comum o desenvolvimento de produtos sem o apoio de metodologias projetuais, o que dificulta a pesquisa técnica e torna-se empírico o conceito de inovação e criatividade do projeto, pois não há parâmetros para que possam ser avaliados. Outro fator decorrente do desenvolvimento de projetos de produtos é a desvalorização do início do processo criativo. Essa falha pode ocorrer por diversos motivos, e um deles é o quesito tempo, em que o produto precisa ser finalizado de acordo com um cronograma, portando, acaba-se por pular etapas consideradas pouco práticas ou muito abstratas. Sendo assim, o projeto acaba partindo quase que diretamente para a metodologia projetual, eliminando a fase de geração de alternativas, o que pode trazer melhorias e redesign, mas pouco contribui para produtos criativos e inovadores.

No desenvolvimento do projeto de carrinho para bebê, tomou-se como partida um jogo de geração de ideias, uma maneira divertida e ao mesmo tempo crítica de gerar e selecionar ideias. Ela estimula o designer a pensar em soluções não óbvias e, ao mesmo tempo, direciona o senso crítico do designer e do grupo, com a finalidade de tornar viável e comunicável a ideia que está sendo concebida. Nas etapas posteriores, em que foram introduzidas as etapas de metodologia projetual, como as análises morfológicas e matrizes, é onde se consegue avaliar as reais viabilidades da ideia, os parâmetros de projeto e seu grau de inovação, no momento em que se compara aos produtos similares.

De modo geral, mesmo que a pesquisa e descrição do projeto de carrinho para bebê que se analisa neste artigo seja muito breve, pode-se observar a necessidade de aplicação de técnicas criativas e de metodologias projetuais. Essas devem ser trabalhadas com a mesma importância e de forma simultânea, pois se observou que é possível agregar novas ideias mesmo quando já se partiu para a metodologia projetual, especialmente onde se busca pelo conceito de projeto.

Observa-se também nesta pesquisa que as técnicas criativas e as metodologias projetuais necessitam de fontes de pesquisas que, muitas vezes, extrapolam o campo de estudo do design. É necessário agregar conhecimento interdisciplinar para que seja possível conhecer, de forma mais aprofundada e coerente, a realidade do usuário, do mercado, dos materiais, da inovação e da criatividade, para que seja mais promissora a inovação de projetos de produtos e o conhecimento do processo projetual pelo designer. 


\section{REFERÊNCIAS}

BACK, N. et al. Projeto integrado de produtos: planejamento, concepção e modelagem. Barueri, SP: Manole, 2008.

BAXTER, M. Projeto de Produto: guia prático para o desenvolvimento de novos produtos. São Paulo: Blucher, 2000.

BONSIEPE, G.; KELLNER, P.; POESSNECKER, H. Metodologia experimental: desenho industrial. Conselho Nacional de Desenvolvimento Científico e Tecnológico, 1984.

CARDOSO, R. Design para um mundo complexo. São Paulo: Cosac Naify, 2012.

CARDOZO, G. A. Proposta de Jogo para a Solução de Problemas Não Estruturados com a Utilização de Técnicas Criativas. 2012. Dissertação (Mestrado) - Universidade Federal do Rio Grande do Sul, Programa de Pós-Graduação em Design.

DEWEY, J. John Dewey on Education: Selected Writings. Chicago: University of Chicago Press, 1974.

FORTY, A. Objeto de desejo: design e sociedade desde 1750. São Paulo: Cosac Naify, 2007.

HARRIS, R. Creative Thinking Techniques. Virtual Salt, 2002. Disponível em:<http://virtualsalt.com/crebook2.htm>. Acesso em 02 jul. 2013.

INMETRO. Regulamento Técnico de qualidade para carrinhos de crianças. 2012.

Disponível em: <http:www.inmetro.gov.br>. Acesso em 14 ago. 2014.

KOWALTOWSKI, D. C. C. et al. (orgs.). 0 processo de projeto em arquitetura. São Paulo: Oficina de Textos, 2011.

MARINA, E. Teste de fogo: conheça prós e contras de seis modelos de carrinhos. Folha de São Paulo, São Paulo, 28 de abril de 2013. Disponível em: <http://www1.folha.uol.com.br/saopaulo/2013/04/1269242-teste-de-fogo-conhecapros-e-contras-de-seis-modelos-de-carrinhos.shtml>. Acesso em 26 jun. 2013.

MUNARI, B. Das coisas nascem coisas. São Paulo: Martins Fontes,1998.

PLENTZ, S. S. Taxonomia para técnicas criativas aplicadas ao processo de projeto. 2011. Dissertação (Mestrado) - Universidade Federal do Rio Grande do Sul, Programa de Pós-Graduação em Design.

SCHÖN, D. A. Educando o profissional reflexivo: um novo design para o ensino e aprendizagem. Porto Alegre: Artmed, 2000. 